\title{
The Visibility of the Disability in Terms of the Social Model: Para Shooting Sport Sample
}

\author{
Meltem Işik Afacan (Corresponding author) \\ Faculty of Sport Sciences, Aydın Adnan Menderes University, Aydın, Turkey \\ E-mail: isik.meltem@adu.edu.tr \\ Ersin Afacan \\ Ministry of Education, Manisa, Turkey \\ E-mail: mentorersin@hotmail.com
}

Received: November 5, $2021 \quad$ Accepted: December 1, 2021

Published: December 31, 2021

doi:10.5296/jei.v7i3.19182 URL: https://doi.org/10.5296/jei.v7i3.19182

\begin{abstract}
The body is one of the ways people express themselves. This is true not only for people without disabilities, but also for people with disabilities. Physical education and sports are one of the methods of disabled people to express themselves physically in society. The aim of this study is to contribute to increasing the visibility of disability in sports in terms of the social model. The sample of the study consists of 11 physically disabled national shooting athletes who have the right to participate in the 2021 Paralympic Games. In the study, a semi-structured interview technique was used in which theoretically, according to De Pauw, his/her thoughts on the visibility of disability in sports were used. In this study, in which qualitative research methods are used, descriptive analysis of the data is performed using both content analysis and in-depth interview. In the study, the demographic characteristics of the participants were determined. In-depth interviews were conducted with 11 people (4 women and $7 \mathrm{men}$ ) who voluntarily participated in the study. Findings obtained from the data after the interviews; The sub-theme of the "obstacles to participation in sports" theme is lack of materials and facilities, the sub-theme of the "attractiveness of the Paralympic Games" is the inadequate promotion of the Paralympic Games, the sub-themes of the "reaction of the social environment" are being congratulated as a positive reaction, and the shooting sport is not known as a negative reaction determined.
\end{abstract}

Keywords: Social model, Sport, Disability, Para shooting sport 


\section{Introduction}

Today, the body is a field of identity. People exhibit what they identify with by the way they relate to their bodies and those of others, the way they respond to other bodies' interventions, their own interventions in their own bodies. They also reveal who they are different from, that is to say, their nominal identities. In this respect, the body is one of the ways for people to express themselves (Okumuş, 2009). This is true not only for people without handicaps, but also for those with handicaps. As a result, one of the ways disabled people express themselves through their bodies within society is physical education and sports.

The change or impairment in the body shape; the incidence of dysmorphic body disorder, being underweight or overweight can negatively affect the social relations of the individual. For example, due to body shape, an individual may avoid getting into social settings (Öngören, 2015). However, sports give disabled individuals the opportunity to gain a sportive identity and at the same time, serve to be distant them from their worthless disabled identities (Bundon, 2019). This situation does not only provide an analytical stance in terms of concretization. It also provides opportunities to question the concepts of interacting bodies such as socially located, socially related and gendered, sexualized, sexually 'oriented', 'racist', 'disabled' (Hockey \& Collinson, 2007). In this regard, the participation of the disabled people in physical education and sports activities contributes positively to their socialization. In addition to this, the attitudes based on love and respect like the habit of planned work, the development of teamwork disposition, the satisfaction of the desire to compete with other people, the tolerant approach to the thoughts and beliefs of others are among the positive effects of physical education and sports activities on the individuals that are physically disabled.

When it comes to physical education and sports for the disabled, the first thing that comes to mind is the Paralympic Games. The Paralympic movement began in 1944 with the German neurosurgeon Ludwig Guttmann when he used sports as part of the rehabilitation for patients with spinal injuries. The philosophy of the Paralympic movement is the philosophy of the individual's self-realization through competitive sport. The Paralympic Games is a great platform for the expression of personal determination and for those that are brave enough to explore their own limits (Bailey, 2008).

\subsection{The Social Model}

The social model is based on the fact that the factors other than the biological existence of human also have the potential to cause disability. According to this model, the experience of being disability is an individual-specific experience with biological, social, political, legal and economic aspects as a product of the intersection between the individual and their social circle (Meşe, 2014). Therefore, the concept of disability in terms of body sociology is an issue that is worth investigating.

The social model reveals the difference between disability, which involves the experience of pressure caused by society, and the physical, cognitive, and sensory impairment (Berghs et al., 2017). For this reason, according to the social model, disabled individuals are not only 
considered as a biological entity, but also as a social being because the sociological perspective necessitates such a view.

The social model asserts that being disabled is the result of the socio-structural barriers that cause to exclude and limit disabled individuals. In this model, for example, inaccessible sports facilities or negative attitudes of coaches cause handicaps rather than individual disabilities (Eklund \& Tenenbaum, 2014).

This social model, which is on being disabled, fundamentally influences the society's worldview and how certain problems are viewed in it, just like in all paradigms. Because this new paradigm is focused on shifting from the physical limitations of certain individuals to the way physical and social circles bring restrictions on certain groups or human categories (Oliver \& Sapey, 1999). Therefore, the social model examines the human body within the framework of the concepts and theories of body sociology. In this examination process, individuals are also evaluated according to their physical disability.

The social model has become influential in promoting the rights of the disabled in the recent years. This model views handicaps as a product of the society's failure to address the needs of a disabled individual as a result of discrimination. In other words, the efforts should focus on fighting discrimination since society deactivates the individual (Stanley, 2005). Because if the fight against discrimination is successful, social equality and justice will be achieved. This creates opportunities for disabled individuals to live more comfortably within the social circle.

In terms of the social circle, being disabled is experienced as the inability to respond to what is a circle created with the purpose of a strong body and meeting the needs independently. Such an experience effectively restricts the independence of the disabled individual, deprives them of the friendship of others and eliminates the concept of equal opportunity (Foster \& Nuttgens, 1997). This situation reveals how important the body is for the disabled individual and how varied characteristics it has.

According to De Pauw, there is a three-stage typology of the visibility of the disabled in sports. This classification offers a different perspective on the issue of being disabled and elite sports. According to this typology, the disabled individuals:

(1) Have experienced invisibility or been excluded from sports due to barriers and difficulties in participating in sports (the invisibility of the disabled in sports).

(2) Are visible but considered inferior to what the others without disabilities have. For example, the position of the Paralympic Games when compared to that of the Olympics. At this stage, the disabled athletes in sports have begun to be visible (the inception of the visibility of the disabled in sports).

(3) Should be visible as athletes within sports. In other words, the disabled individuals are becoming more and more visible as athletes in sports environments (the acknowledgment of the visibility of the disabled in sports) (De Pauw, 1997). 


\section{Mll Macrothink}

\section{Method}

Despite the fact that there were scales regarding social visibility, it was aimed to measure visibility with three questions since no sports-specific scales were found measuring the visibility of the disabled. Because, according to De Pauw, there is a three-stage typology in terms of the visibility of the disabled in sports. According to this typology, it was estimated that the athletes would be able to convey the facts more sincerely thanks to the fact that the questionnaire prepared was short and easy to respond.

The research is a descriptive study as it generally aimed to measure the social visibility of the physically disabled shooting athletes. The demographic characteristics of the participants were also obtained within the scope of the study. A total of 11 participants was thought to reflect an adequate ratio for the Paralympic Games. It is also estimated that this research will be an example for the studies which will involve other sports branches that will represent Turkey in the Paralympic Games.

\subsection{Sample}

The research was carried out on the athletes who would represent Turkey in the shooting branch at the 2021 Paralympic Games. Due to the Covid-19 pandemic, the athletes were reached via phone, and survey method was utilized. For the research, convenience sampling method was chosen in order to be able to reach a wide range of athletes who would represent Turkey in the Paralympic Games. After the questionnaires obtained were checked, a total of 11 questionnaires appropriate for the analysis were put into the evaluation process. The demographic characteristics of the participants were given in Table 1. 
Table 1. The demographic characteristics of the participants

\begin{tabular}{|c|c|c|}
\hline & $\mathbf{N}$ & $\%$ \\
\hline \multicolumn{3}{|l|}{ Gender } \\
\hline Women & 4 & 36.4 \\
\hline Men & 7 & 63.6 \\
\hline Total & 11 & 100 \\
\hline \multicolumn{3}{|l|}{ Age } \\
\hline $20-29$ & 1 & 9.1 \\
\hline $30-39$ & 3 & 27.3 \\
\hline $40-49$ & 6 & 54.5 \\
\hline $50-59$ & 1 & 9.1 \\
\hline Total & 11 & 100 \\
\hline \multicolumn{3}{|l|}{ Profession } \\
\hline Athlete & 4 & 36.4 \\
\hline Officer & 6 & 54.5 \\
\hline Architect & 1 & 9.1 \\
\hline Total & 11 & 100 \\
\hline \multicolumn{3}{|l|}{ Education status } \\
\hline High school & 5 & 45.4 \\
\hline Associate Degree & 2 & 18.2 \\
\hline Undergraduate & 4 & 36.4 \\
\hline Total & 11 & 100 \\
\hline \multicolumn{3}{|l|}{ Experience } \\
\hline $10-14$ & 3 & 27.3 \\
\hline $15-19$ & 7 & 63.6 \\
\hline $20-24$ & 1 & 9.1 \\
\hline Total & 11 & 100 \\
\hline
\end{tabular}

The gender distribution of the athletes who would represent Turkey in the shooting branch at the 2021 Paralympic Olympics was; $36.4 \%$ female and $63.6 \%$ male. 54.5\% of these participants, which corresponded to more than half of the athletes, were between the age 


\section{Macrothink}

range of 40-49. In other words, it could be stated that the national team was a male-dominated group, with a middle-age average.

In the research, $36.4 \%$ of the participants did not have a profession other than being an athlete. While $54.5 \%$ of them were civil servants, only 1 participant had an independent profession as an architect. Nearly half of the participants were high school graduates (45.4\%), whereas almost the other half were undergraduates $(36.4 \%)$. Only 2 of the participants were associate degree graduates. In terms of education level, this situation can be considered as positive because despite being disabled, more than half of the participants had university education.

In terms of sports experience, $63.6 \%$ of the participants had been performing shooting as a sport for 15 to 19 years. Considering the fact that the most inexperienced athlete had a 10 -year experience, it can be stated that the national shooting team was composed of highly experienced athletes.

When this table is generalized and the average of the Turkish shooters who are entitled to participate in the Paralympic Games is considered, it can be expressed that "the participant group is a middle-aged, male-dominant, mostly civil servant and undergraduate sports group who have been performing sports for around 15 years

\subsection{Data Collection Tool}

The survey was composed of two sections. In the first section, the demographic information including age, gender, educational status, years of experience and occupation was presented. In the second section, there was a three-question section on the visibility of In terms of education level, this situation can be considered as positive because despite being disabled, more than half of the participants had university education. in sports. In this section, the Paralympic shooters were asked to express their views on the barriers to participating in sports, the comparison of the Paralympic Games with the Olympic Games, and the perspective of the social circle towards shooting as a sport. 


\section{Results}

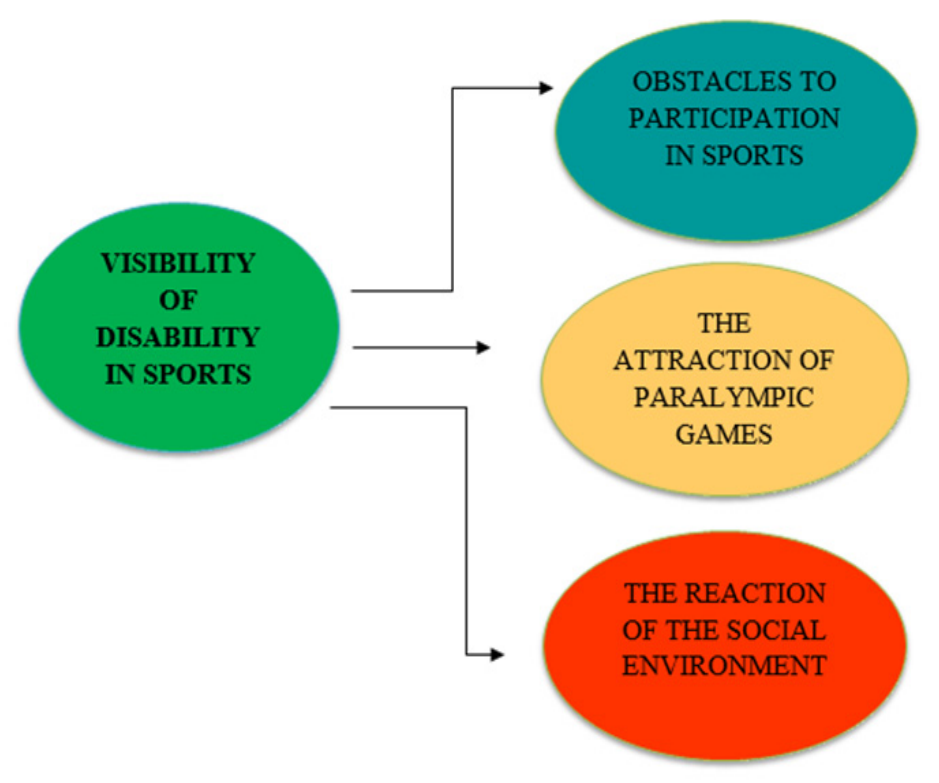

Figure 1. Visibility of disability in sports by shooters

The main themes of the three questions asked to the participants so as to determine their views on the visibility of the disability in sports are presented above. The analyses of these themes are as follows.

\subsection{Main Theme: The Barriers Preventing a Physically Disability Individual from} Participating in the Shooting Sports

\begin{tabular}{|l|l|l|}
\hline Codes that appeared as a result of the interview & Sub-themes & Participents \\
\hline Insufficient facility facilities & Facility & P1-P4-P5-P6-P7-P8-P9 \\
\hline Difficulty in procurement of materials & Material & P2-P3-P4-P6-P7-P8-P9 \\
\hline Lack of training of trainers & Trainer & P1-P5-P9 \\
\hline Not very well known & Promotion & P3-P5-P6-P7-P9 \\
\hline Starting sports late & Starting a Sport & P1-P5 \\
\hline Insufficient awareness of sports for people with disabilities & Sports Awareness & P1-P5-P8-P10-P11 \\
\hline Transportation problems & Transportation & P2-P4-P8 \\
\hline Economic impossibilities & Economic & P1-P4 \\
\hline
\end{tabular}




\section{Macrothink}

The statements of the participants regarding the sub-theme of "facility" are as follows:

P1: "The facilities are insufficient. Architectural obstacles such as narrow doors and stairs are sometimes a problem for us."

P4: "There are few opportunities for the disabled within the facilities. For example, most of the rooms we use are not suitable for us. The rooms should be close to the elevator, and the door handles should open easily."

P5: "The facilities are not sufficient for the shooting branch."

P6: "The number of facilities is not enough. Lack of facilities is a major barrier for shooting."

P7: "The facilities are insufficient."

P8: "The number of facilities is low."

P9: "The lack of facilities is a serious barrier for the disabled individuals to participate in shooting sports."

When these views of the participants are evaluated, it can be noticed that the inadequacy of the sports facilities creates a serious barrier for the disabled individuals to participate in shooting sports because the facilities where disabled individuals do sports need to be specially arranged for them.

The statements of the participants regarding the sub-theme of "equipment" are as follows:

P2: "The fact that shooting equipment is not easily accessible is a serious barrier for our disabled people to participate in the shooting sports."

P3: "The fact that the shooting equipment is expensive is an important problem for our disabled people to participate in the shooting sports."

P4: "It is not easy to supply technical equipment of the shooting sports."

P6: "The lack of sufficient equipment for shooting in the facilities makes it difficult for the disabled to participate in the shooting sports."

P7: "I can say that the equipment is insufficient."

P8: "There are problems regarding accessible equipment. Due to the equipment problem, the disabled individuals do not want to participate in the shooting sports."

P9: "The lack of equipment is an important problem for the disabled individuals to participate in the shooting sports."

When these views of the participants are evaluated, it can be stated that the issue of equipment is important in participation of the disabled individuals in the shooting sports. Considering such difficulties as the fact that the equipment is expensive and not easily accessible, it is necessary to find a solution to the equipment problem in order for the disabled individuals to do sports more comfortably. 


\section{Macrothink}

The statements of the participants regarding the sub-theme of "coach" are as follows:

P1: "In my opinion, coaches are not at a sufficient level in h disabled sports."

P5: "The coaches in the provinces do not know what sports the disabled are able to do."

P9: "The lack of adequately equipped trainers is an important barrier for the disabled people to participate in the shooting sports."

When these views of the participants are evaluated, the coaches are extremely significant in the participation of the disabled individuals in the shooting sports. It is very important for the coaches to have adequate knowledge and equipment in this field for the disabled individuals to do sports appropriately.

The statements of the participants regarding the sub-theme of "recognition" are as follows:

P3: "Shooting as a sport is not well known by the disabled."

P5: "Disabled shooting sport is not known enough in Turkey."

P6: "There is not enough promotion for our disabled citizens regarding shooting as a sport."

P7: "The sport of shooting is not advertised enough."

P9: "Shooting branch is not adequately promoted by related institutions and organizations."

When these views of the participants are evaluated, it is necessary to promote and advertise this sport well in order for the disabled individuals to participate in the shooting sports because there is a serious deficiency in our country regarding this issue.

The statements of the participants regarding the sub-theme of "starting sports" are as follows:

P1: "Starting late to sports prevents disabled people from participating in the shooting sports."

P5: "Disabled people meet sports very late. For this reason, they cannot participate adequately in the shooting sports."

When these views of the participants are evaluated, it is a beneficial for the disabled individuals to begin the shooting sports before it is too late in terms of age because it becomes more difficult for the disabled individuals to participate in the shooting sports as they grow older.

The statements of the participants regarding the sub-theme of "sports awareness" are as follows:

P1: "In our country, sports awareness is weak. For this reason, it is difficult for the disabled to begin the shooting branch."

P5: "The lack of sports awareness for the disabled in primary schools."

P8: "Most of the disabled individuals do not have enough knowledge about sports branches. For this reason, their awareness of sports is weak." 


\section{Macrothink}

P10: "The managers who are not like us, who do not understand people with disabilities."

P11: "The mindset is a barrier. However, if the disabled individual really wants, nothing can prevent them from doing sports."

When these views of the participants are evaluated, the fact that the sports culture in our country is not developed enough, and accordingly the lack of sports awareness in our sports people are important problem sources for the disabled individuals to participate in the shooting sports.

The statements of the participants regarding the sub-theme of "transportation" are as follows:

P2: "Transportation problems are a serious barrier for the disabled people to do the shooting sports."

P4: "Disabled people stay away from the shooting sports due to transportation problems."

P8: "Accessibility is very difficult for the disabled locally."

When these views of the participants are evaluated, the transportation problem of a disabled individual in participating in the shooting sports attracts attention. Considering the fact that the disabled individuals have difficulty in using public transport, it should be considered normal for the participants to see the theme of transportation as a barrier.

The statements of the participants regarding the sub-theme of "economy" are as follows:

P1: "It is very difficult for the disabled people with economic problems to do the shooting sports."

P4: "Economic inadequacies prevent the disabled from engaging in the shooting sports."

When these views of the participants are evaluated, it is understood that a disabled individual may have economic difficulties in participating in the shooting sports. It is also possible to associate the issue of "being expensive" in the sub-theme of "equipment" with this sub-theme.

3.2 Main Theme: Are the Olympic Games or the Paralympic Games More Popular in the Society?

\begin{tabular}{|l|l|l|}
\hline Codes that appeared as a result of the interview & Sub-themes & Participents \\
\hline Olympics Game & Promotion & P2-P5-P6-P7-P8-P9-P10 \\
\hline Paralympics Game & Compassion Curiosity Success & P1-P3-P4-P11 \\
\hline
\end{tabular}

While 7 of the participant athletes have claimed that the Olympic Games attract more attention in the society, 4 of the participant athletes have stated that the Paralympic Games attract more attention. While making this comparison, the only reason presented by the 
athletes who claimed the Olympic Games is recognition.

The statements of the participants who have argued that the Olympic Games attract more attention in the society are as follows:

P2: "Olympic Games attract more attention. Because it is known and recognized more than the Paralympic Games."

P5: "Olympic Games seem to be far ahead. Because it attracts more attention and it is promoted more.

P6: "More attention is paid to the Olympic Games as a source of advertising and promotion."

P7: "Olympic Games attract more attention. Because the Paralympic Games are less well-known."

P8: "Olympic Games are known more. Because it has an extensive promotion and advertisement network."

P9: "As the Olympic Games are promoted better, they attract more attention in the society."

P10: "More attention is paid to the Olympic Games. Because the presidents and managers work harder on its promotion than the officials of the Paralympic Games."

The statements of the participants who argued that the Paralympic Games attract more attention in the society are as follows:

P1: "I think the Paralympic Games attract more attention. Because our people are compassionate, and they want the disabled people to be successful."

P3: "When our society, which sees the disabled people as passive individuals in daily life, wonders what we will do and watches our games, they respect us with faith and pride."

P4: "The Paralympic Games attract more attention. Because success is at the highest level despite the barriers in difficult conditions."

P11: "Paralympic Games attract more attention. Because our people wonder what the disabled people can do. The life perspectives of those who see the success of the disabled individuals like us are changing.

\subsection{Main Theme: Positive Views of the Social Circle towards the Participants}

\begin{tabular}{|l|l|l|}
\hline Codes that appeared as a result of the interview & Sub-themes & Participents \\
\hline Getting Support from People & Support & P1-P2-P4-P5-P6-P9 \\
\hline Pride of People & Pride & P3-P7-P8-P10-P11 \\
\hline
\end{tabular}

The positive views of the social circle towards the participants are divided into two groups. 


\section{Macrothink}

These are coded as "people's support" and "people's pride". For those who get support from people, the theme is "support" because it is important and necessary for the disabled individual to get all kinds of support and help while doing sports.

The statements of the participants emphasizing the sub-theme of "support" are as follows:

P1: "Since I started sports, I have always received support from my social circle, especially from my family."

P2: "My social circle was always with me. People gave me all kinds of financial and spiritual support."

P4: "My social circle, especially my friends, always support the development of the shooting sports and my success."

P5: "I receive positive approaches due to the sports I do in every setting I get in. People support me in every way."

P6: "Before I became a competitor in this sport, I was performing it as a hobby. But with the encouragement and support of my social circle, I became a competitor."

P9: "Although my circle did not know the importance of this sport, they supported me so that I could be happy. My friends at the institution where I work always gave countenance to me.

The statements of the participants emphasizing the sub-theme of "pride" are as follows:

P3: "Together with the impact of my achievements, my social circle congratulates me by saying 'you are stronger than us', 'we do not even see you as a disabled person', well done, you rock!', 'we are proud of you'."

P7: "My social circle always says that they are proud of me for representing my country."

P8: "My circle states that they have known the shooting sports thanks to me, and they express anytime that they are proud of me."

P10: "I got an Olympic quota by working really hard. Therefore, the people around me have begun to say that they are proud of me."

P11: "My social circle, especially my disabled friends, approached me positively by saying "we are proud of you."

3.4 Main Theme: Negative Views of the Social Circle towards the Participants

\begin{tabular}{|l|l|l|}
\hline Codes that appeared as a result of the interview & Sub-themes & Participents \\
\hline To be careful & Fear & P1-P2-P4-P5-P6-P10-P11 \\
\hline Sports with a Rifle & Culture & P3-P7-P8-P9 \\
\hline
\end{tabular}




\section{Macrothink

The negative views of the social circle towards the participants are divided into two groups. These are coded as "being careful" and "the sports performed with a rifle". The theme of the code "being careful" is "fear" because any kind of carelessness may cause various injuries for the disabled individual while doing the shooting sports.

The statements of the participants emphasizing the sub-theme of "fear" are as follows:

P1: "My family had a negative reaction at first for fear that I would be harmed by the shooting sports because it is a sport performed with a rifle."

P2: "My social circle tried to discourage me for fear of being injured when I started the shooting sports."

P4: "My family, relatives and social circle were afraid that I would not be careful enough while doing the shooting sports."

P5: "People are afraid of what they don't know. For this reason, when my social circle heard the name of shooting, they would often warn me by saying "may you get no harm from it."

P6: "As there is a rifle involved and the athletes are the disabled individuals, my people were afraid and reluctant on my behalf at first."

P10: "In the very beginning, my family did not want it because they were afraid that something bad would happen to me. I got married, and this time my wife reacted negatively with the same fear."

P11: "My social circle tried to prevent me from doing the shooting sports on the basis of fear saying "What does a girl have to do with a gun? You are already disabled. Just sit and do nothing."

The statements of the participants emphasizing the sub-theme of "culture" are as follows:

P3: "When I first started the shooting sports, I had a negative reaction as 'What does a woman have to do with a gun? You cannot see it in our family!"

P7: "My social circle objected me at the very beginning because they did not know what the shooting sports was. Because they were not brought up in such a culture."

P8: "My social circle mocked at first by saying that 'Shooting? What are you shooting? Shooting an arrow or shot puts?'. They did not know the shooting sports because their sports culture was weak.

P9: "My circle was far from the shooting sports, and even football, in terms of culture. For this reason, they exhibited a negative perspective in terms of seeing me starting sports at the very beginning."

\section{Discussion}

This qualitative study was conducted with 11 Turkish para shooting athletes that were physically disabled. The aim was to reveal the barriers faced towards the para shooting sports in terms of the social model, the attention paid by the society to the Paralympic Games, and 
the positive and negative perspectives of the social circle. This study, which is specific to para shooting, is deemed important in terms of the possibility of encouraging para athletes to increase their quality experience.

Sports offer a variety of opportunities for the people that are not disabled. Contrary to this situation, sports offer fewer opportunities for the disabled. In this regard, people pay less attention to sports formations called the sports for the disabled or Paralympic sports. The heterogeneous denomination of the limited existing literature reveals the conceptual, ethical and political dimensions of the discussions for the disabled people (Edwards \& McNamee, 2015). Therefore, the social model is a fundamental contribution to our knowledge and understanding of the disabled provided by the disabled academic staff, disabled people and their movements (Terzi, 2004). The social model of the disabled associates an individual's disadvantage with the combination of the personal characteristics and social circle. The model seems to have had a profound impact on academics, politics and law since the 1970s (Samaha, 2007). Social theories are often developed so as to provide a clearer understanding of a situation or a problem. The 'Social Model', which has various forms, is currently the dominant model for the study of the disabled, and deals with the disabled within a socio-political framework based primarily on a 'social constructivist' perspective (Dewsbury et al., 2004). The social model recognizes the existence of disorders and physiological differences. It handles these disorders and physiological differences without adding value judgments like 'normality', and emphasizes the aspects of our world that can be altered (Priestley, 1998).

The Paralympic shooting athletes who participated in our research were asked the reasons for the barriers of a physically disabled individual to participate in the shooting sports. When the responses given were evaluated, the first reason mentioned was that there were not enough opportunities for equipment supply, and the equipment was expensive. In another study in which the cost was an effective reason for the visually disabled individuals to participate in sports, it was emphasized that the most frequently mentioned environmental barrier mentioned by the Dutch Paralympic athletes was the inadequacy of the sports facilities (Jaarsma et al., 2014b).

When the responses given to the question of the barriers preventing the physically disabled individuals from participating in the shooting sports were evaluated, the second reason mentioned was the lack of sports awareness for the disabled. It is important that physical education teachers should have a high level of awareness, especially in the process of encouraging physically disabled individuals at school to participate in sports. Because the importance of being knowledgeable about disabled sports and how the physically disabled students will be guided to begin sports should be emphasized by physical education teachers. According to the views of the physically disabled athletes who participated in a study, the perception of disability within the society is associated with the long-standing reduced abilities, and the persistence of this belief negatively affects the participation in sports (Ballas et al., 2020). This is supported by the concept of the social model of the disabled, which is defined as the fact that any physical impairment is a limitation that arises as a result of social organization rather than being autochthonous (World Health Organization, 2001). 
When the responses given to the question of the barriers to the participation of the physically disabled individuals in the shooting sports were evaluated, it could be noticed that last but not least barrier to the para shooting sports was the fact that the shooting sports was not adequately promoted. In a study with Australian para athletes, which revealed a similar situation with our study, together with the fact that the Paralympic Games were promoted at such low levels, the lack of advertisement in para sports were also mentioned. Para athletes stated that they believed increasing advertisement and awareness in the para sports would enable those with similar backgrounds to them to participate in sports at a much earlier period and encourage more and more people with physical disabilities to begin doing sports (Ballas et al., 2020).

When the second main theme in the research was considered, it was revealed that 7 of the participant athletes expressed the Olympic Games attracted more attention in the society, while the other participants stated the Paralympic Games attracted more attention. While making this comparison, the only reason mentioned by the athletes who put forward the Olympic Games attracted more attention was recognition. In the study conducted by Ballas et al. (2020), physically disabled elite athletes stated that the Paralympic Games should be promoted similarly to the Olympic Games, and that they were a growing group deserving more and more recognition.

In the third main theme, the positive views of the social circle towards the participants were divided into two groups. These were coded as people's support and people's pride. When the responses given were evaluated, it could be stated that it was important and necessary for the disabled individual to get all kinds of support and help while doing sports. Because it is well known that the bodily benefits of being physically active are motivating for many people living with disabilities (Kehn \& Kroll, 2009). In this regard, as a result of a study examining the barriers and facilitators in front of the sports participation in visually disabled individuals, it was mostly emphasized that family support was the most important environmental facilitator (Jaarsma et al., 2014a). In a different study by Jaarsma with the Paralympic athletes, it was stated that the most frequently mentioned environmental facilitator was social support (Jaarsma et al., 2014b). In many ways, sports is designed to highlight and elevate the extremes of bodily excellence. Under these circumstances, it is possible to see why the idea of elite sports for the disabled, and in some cases any sports, is disapproved by some people. For this reason, it is emphasized that the conclusion of such a situation for potentially disabled athletes may be that their dreams and wishes might be regarded with humiliation or mocking even by their own circle (Brittain, 2004).

The negative views of the social circle towards the participants were divided into two groups. These were coded as being careful and the sports performed with a rifle. The theme of the code of being careful was fear. Because any kind of carelessness can cause various injuries for the disabled individual while doing the shooting sports. In a study conducted with elite level physically disabled athletes, it was exhibited that the barriers to participation in sports involved the fear of being judged due to physical disorders and the fear of higher injury risks (Ballas et al., 2020). 


\section{Conclusion and Suggestions}

The Paralympic Games is an organization in which disabled athletes participate. Para in the word Paralympic, which is a combination of the words "Para" and "Olympics", means "equal". In other words, the Paralympic Games were given this name since they are deemed the equivalent of the Olympic Games (Winnick, 2005). Therefore, Paralympic athletes and Olympic athletes compete under the same conditions. Despite this, the Olympic Games are ahead of the Paralympic Games in every aspect, especially in terms of the budget. For this reason, this study is deemed significant as it examines the visibility of the Paralympic Games and athletes in terms of people and societies. Besides, it is also deemed valuable in terms of being an example for similar further studies. Therefore, it will be possible to put forward clearer views about the visibility status of the Paralympic Games and athletes in terms of people and societies, and about what should be done to increase this visibility.

The Paralympic Games is a huge platform in which disabled individuals can exhibit their talents and abilities to the whole world. For this reason, better advertisement and promotion of this organization will increase the ratio of awareness within the society. This situation will also increase the expectation norm of the physically disabled individuals. When easy access to sports is provided for the disabled within the society, and their participation is encouraged, it will be ensured that physically disabled individuals will be more involved in this platform, their physical self-confidence will be increased, they will be more courageous in terms of social participation and more passionate in terms of achieving their goals.

\section{References}

Bailey S. (2008). Athlete First: A History of the Paralympic Movement. John Wiley \& Sons, Ltd. https://doi.org/10.1080/17460263.2012.694633

Ballas, J., Buultjens, M., Murphy, G., \& Jackson, M. (2020). Elite-level athletes with physical impairments: Barriers and facilitators to sport participation. Disability \& Society, 1-20. https://doi.org/10.1080/09687599.2020.1862642

Berghs, M., Atkin, K., Graham, H., Hatton, C., \& Thomas, C. (2017). Public health, research and rights: the perspectives of deliberation panels with politically and socially active disabled people. Disability \& Society, 32(7), 945-965. https://doi.org/10.1080/09687599.2017.133 9588

Brittain, I. (2004). The role of schools in constructing self - perceptions of sport and physical education in relation to people with disabilities. Sport, Education and Society, 9(1), 75-94. https://doi.org/10.1080/1357332042000175827

Bundon, A. (2019). Injury, pain and risk in the Paralympic movement. The Suffering Body in Sport (pp. 71-87). Emerald Publishing Limited. https://doi.org/10.1108/s1476-2854201900 00012007

DePauw, K. P., \& Sherrill, C. (1994). Adapted physical activity: present and future. Physical Education Review, 17(1), 6-13. https://doi.org/10.1007/978-4-431-68272-1_2 


\section{Macrothink}

Dewsbury, G., Clarke, K., Randall, D., Rouncefield, M., \& Sommerville, I. (2004). The anti social model of disability. Disability \& Society, 19(2), 145-158. https://doi.org/10.1080/09687 59042000181776

Edwards, S., \& McNamee, M. (2015). Disability and paralympic sport philosophy. Routledge Handbook of the Philosophy of Sport (pp. 300-314). Routledge, London. https://doi.org/ 10.4324/9780203466261-21

Eklund, R. C., \& Tenenbaum, G. (2014). Encyclopedia of sport and exercise psychology. Sage Publications, California. https://doi.org/10.4135/9781483332222

Foster, L., \& Nuttgens, P. (1997). Access to the historic environment: Meeting the needs of disabled people. Routledge, London.

Hockey, J., \& Collinson, J. A. (2007). Grasping the phenomenology of sporting bodies. International Review for the Sociology of Sport, 42(2), 115-131. https://doi.org/10.1177/ 1012690207084747

Jaarsma, E. A., Dekker, R., Koopmans, S. A., Dijkstra, P. U., \& Geertzen, J. H. (2014a). Barriers to and facilitators of sports participation in people with visual impairments. Adapted Physical Activity Quarterly, 31(3), 240-264. https://doi.org/10.1123/apaq.2013-0119

Jaarsma, E. A., Geertzen, J. H., de Jong, R., Dijkstra, P. U., \& Dekker, R. (2014b). Barriers and facilitators of sports in Dutch Paralympic athletes: An explorative study. Scandinavian Journal of Medicine \& Science in Sports, 24(5), 830-836. https://doi.org/10.1111/sms.12071

Kehn, M., \& Kroll, T. (2009). Staying physically active after spinal cord injury: A qualitative exploration of barriers and facilitators to exercise participation. BMC Public Health, 9(1), 1-11. https://doi.org/10.1186/1471-2458-9-168

Meşe, İ. (2014). Engelliliği açıklayan sosyal model nedir? Sosyal Politika Çalışmaları Dergisi, 33, 79-92. https://doi.org/10.21560/spcd.17773

Okumuş, E. (2009). Bedene müdahalenin sosyolojisi. Şarkiyat İlmi Araştırmalar Dergisi (Sayı: II Kasım, 2009).

Oliver, M., \& Sapey, B. (1999). Social work with disabled people. Palgrave. New York. https://doi.org/10.1007/978-1-349-14823-3

Öngören, B. (2015). Sosyolojik açıdan sağlıklı beden imgesi. Sosyal ve Beşeri Bilimler Araştırmaları Dergisi, 16(34), 25-45.

Priestley, M. (1998). Constructions and creations: Idealism, materialism and disability theory. Disability \& Society, 13(1), 75-94. https://doi.org/10.1080/09687599826920

Samaha, A. M. (2007). What good is the social model of disability? The University of Chicago Law Review, 74(4), 1251-1308. https://doi.org/10.2307/20141862

Stanley, K. (2005). The missing million: The challenges of employing more disabled people. Working futures: Disabled people, employment policy and social inclusion (pp. 29-44). 
British Library Cataloguing in Publication Data. https://doi.org/10.2307/j.ctt9qgsms.10

Terzi L. (2004). The social model of disability: A philosophical critique. Journal of Applied Philosophy, 21(2), 141-157. https://doi.org/10.1111/j.0264-3758.2004.00269.x

WHO (World Health Organization). (2001). International Classification of Functioning, Disability and Health: ICF. Geneva: World Health Organization.

Winnick, J. P. (2005). Adapted Physical Education and Sports (4th ed.). Human Kinetics.

\section{Copyright Disclaimer}

Copyright for this article is retained by the author(s), with first publication rights granted to the journal.

This is an open-access article distributed under the terms and conditions of the Creative Commons Attribution license (http://creativecommons.org/licenses/by/3.0/). 